\title{
Organization of GABA-Containing Neurons in Some Extrapyramidal Nuclei
}

\author{
H.C. FIBIGER
}

SUMMARY: Nuclei of the extrapyramidal system contain among the highest levels of GABA and its synthesizing enzyme glutamic acid decarboxylase $(G A D)$ in the central nervous system. In recent years the anatomical organization of GABAergic neurons in the extrapyramidal system has been the subject of considerable experimental enquiry. In this note, current knowledge concerning the origin and projections of GABAergic neurons in certain extrapyramidal nuclei is briefly reviewed.

RESUME: Les noyaux du système extrapyramidal contiennent parmi les plus hauts niveaux de GABA et de son enzyme de synthèse, la décarboxylase de l'acide glutamique (GAD) dans le système nerveux central. Au cours des dernières années la recherche sur l'organisation anatomique des neurones GABA-ergiques du système extrapyramidal a été très active. Nous présentons une revue de nos connaissances sur l'origine et les projections de ces neurones $G A B A$ ergiques dans certains noyaux extrapyramidaux.

From the Division of Neurological Sciences,
Department of Psychiatry, University of British Columbia, Vancouver.

Reprint requests to H.C. Fibiger, Department of Psychiatry, University of British Columbia, Vancouver, British Columbia, Canada V6T IW5.
The precise origin of GABAcontaining afferents to the substantia nigra (SN) has been the subject of some controversy. Kim et al. (1971) first showed that hemitransections between striatum and $\mathrm{SN}$ in the rat produced a large decrease in nigral GABA. Furthermore, it was found that large striatal lesions, which also damaged the globus pallidus (GP), significantly decreased the GABA content of the $\mathrm{SN}$ and on these grounds it was suggested that the striatonigral projection was GABAergic. Similar results were subsequently obtained by this group in the baboon (Kataoka et al., 1975). Hattori et al. (1973) confirmed that hemitransections at the level of the hypothalamus greatly reduced nigral GAD activity, but they reported that striatal hemitransections just anterior to GP, failed to significantly affect nigral GAD. On the basis of these results, Hattori et al. (1973) first suggested that the majority of the striatonigral projection was not GABAergic and that the GABAergic innervation of the $\mathrm{SN}$ originated either in the GP or in the tail of the striatum lateral to GP. The existence of a pallidonigral projection was subsequently demonstrated by Hattori et al. (1975) and later confirmed by a number of laboratories (Brownstein et al., 1977; Grofova, 1975; Kanazawa et al., 1976).

Nagy et al. (1978a) replicated and extended the earlier observations of Hattori et al. (1973). Striatal hemitransections anterior to GP or large electrolytic lesions of the head of the striatum failed to significantly alter nigral GAD activity. These results indicate that in the rat the majority of nigral GAD is contained in axon terminals whose cell bodies are located caudal to the rostral pole of the GP. There now appears to be considerable consensus regarding this conclusion because on the basis of similar lesion studies, Brownstein et al. (1977) have also concluded that nigral GAD originates entirely from neurons located in the posterior striatum and possibly the anterior GP. Further, Fonnum et al. (1978) have provided evidence that the striatal/pallidal source of nigral GAD activity is entirely postcommissural.

While the above studies have served to delimit the origin of the descending GABAergic innervation of the SN, they do not firmly differentiate between potential striatal and pallidal sources. To address this problem directly, experiments were undertaken to lesion perikarya in the globus pallidus with kainic acid. Because kainic acid is a relatively selective neurotoxin for neuronal perikarya (Mason and Fibiger, 1979), it was hypothesized that this approach could be used to lesion the pallidonigral projection while sparing the fibres of the striatonigral system that pass through the GP. Kainic acid lesions of the GP produced a significant decrease in GAD activity in the GP suggesting the presence of GADcontaining perikarya in this nucleus. Histological examination of identically lesioned animals indicated that with the exception of the caudal tip, destruction of neurons within the GP was virtually complete. These lesions failed to decrease significantly GAD activity in the SN indicating that the GP is not the source of the massive GABAergic innervation of the SN. A source with the striatum is therefore indicated (Nagy and Fibiger, 1980).

At present, the question concerning the exact striatal source of nigral GAD must necessarily be approached by the process of elimination. Coronal hemitransections just anterior to the GP do not significantly decrease nigral GAD (Brownstein et al., 1977; Fonnum et al., 1978; Hattori et al., 1973; Jessell et 
al., 1978; Nagy et al., 1978a). Neither does the tail of the striatum appear to be the major source because lesions of this region produce only a small decrease in nigral GAD (Brownstein et al., 1977; Nagy, 1979). It can tentatively be concluded, therefore, that in the striatal GABAergic neurons that project to the $\mathrm{SN}$ are located in a shell that surrounds the anterior, lateral and perhaps dorsal borders of the GP. Finally, it should also be noted that not all nigral GAd activity is associated with this descending projection. A minor portion appears to be associated with GABAergic perikarya located in the SN itself (Nagy et al., 1978c). The latter neurons appear to be the source of nigral projections to the tectum and certain thalamic nuclei (Vincent et al., 1978).

While the GABAergic neurons of the GP do not project to the SN, there is evidence in the cat that they innervate the subthalamic nucleus (Fonnum et al., 1978). Similarly, the entopeduncular nucleus is known to be the origin of the GABAergic projection to the lateral habenula (Nagy et al., 1978b). In addition to these efferent projections, there is now substantial evidence that these pallidal nuclei receive a major GABAergic innervation from the striatum. Specifically, coronal hemitransections anterior to the GP result in large decreases in GAD activity in both the globus pallidus and entopenduncular nucleus (Fonnum et al., 1978; Nagy et al., 1978a). Apart from demonstrating the GABAergic nature of some striatopallidal and striatoentopeduncular fibres, these results also indicate that many GABAergic neurons that innervate the globus pallidus do not appear to send collaterals to the substantia nigra. Thus, hemitransections and striatal lesions anterior to the globus pallidus that resulted in large decreases in pallidal and entopenduncular GAD did not significantly affect the activity of this enzyme in the SN. Therefore, to some considerable extent different populations of striatal GABAergic neurons project to the pallidal nuclei on the one hand and the substantia nigra on the other. In the rat, the majority of the former are located precommissurally, while the latter are located postcomissurally. The above considerations are summarized in Figure 1.

\section{REFERENCES}

BROWNSTEIN, M.J., MROZ, E.A., TOPPAZ, M.L. and LEEMAN, S.E. (1977). On the origin of substance $P$ and glutamic acid decarboxylase (GAD) in the substantia nigra. Brain Res. 135, 315-323.

FONNUM, F., GOTTESFELD, $Z$. and GROFOVA, I. (1978). Distribution of glutamate decarboxylase, choline acetyltransferase and aromatic amino acid decarboxylase in the basal ganglia of normal and operated rats. Evidence for striatopallidal, striatoentopeduncular and striatonigral GABAergic fibres. Brain Res. 143, 125-138.

FONNUM, F., GROFOVA, I. and RINVIK, E. (1978). Origin and distribution of glutamate

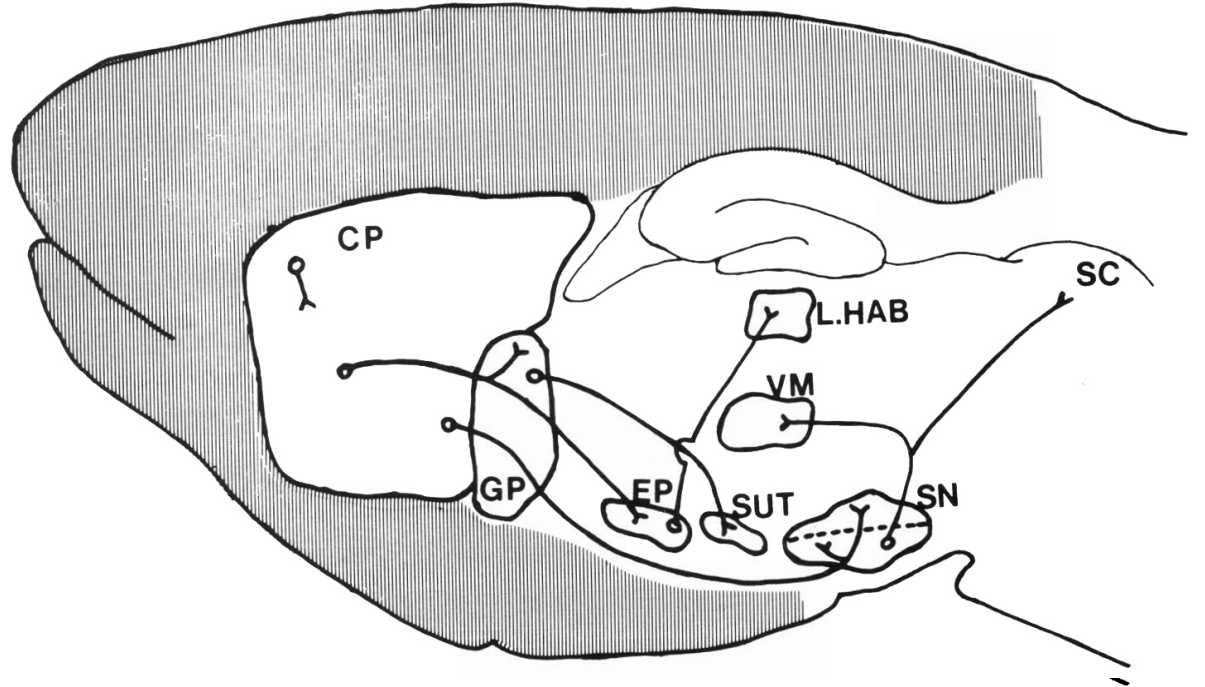

Figure 1 - Organization of some GABAergic projections in the extrapyramidal system. See text for details. decarboxylase in the nucleus subthalamicus of the cat. Brain Res. 153. 370-374.

GROFOVA, I. (1975). The identification of striatal and pallidal neurons projecting to the substantia nigra. An experimental study by means of retrograde axonal transport of horseradish peroxidase. Brain Res. 91, 286291.

HATTORI, T., FIBIGER, H.C. and McGEER, P.L. (1975). Demonstration of a pallidonigral projection innervating dopaminergic neurons. J. comp. Neurol. 162, 487-504.

HATTORI, T., McGEER, P.L., FIBIGER, H.C. and MCGEER, E.G. (1973). On the source of GABA-containing terminals in the substantia nigra. Electron microscopic autoradiographic and biochemical studies. Brain Res. 54, 103-114.

JESSELL, T.M., EMSON, P.C., PAXINOS, G. and CUELLO, A.C. (1978). Topographic projections of substance $P$ and GABA pathways in the striato- and pallido-nigral system: A biochemical and immunohistochemical study. Brain Res. 152, 487-498.

KANAZAWA, I., MARSHALL, G.R. and KELLY, J.S. (1976). Afferents to the rat substantia nigra studied with horseradish peroxidase, with special reference to fibers from the subthalamic nucleus. Brain Res. $115,485-491$.

KATAOKA, K., BAK, I.J., HASSLER, R., KIM, J.S. and WAGNER, A. (1974). LGlutamate decarboxylase and choline acetyltransferase activity in the substantia nigra and the striatum after surgical interruption of the strionigral fibers in the baboon. Exp. Brain Res. 19, 217-227.

KIM, J.S., BAK, I.J., HASSLER, R. and OKADA, Y. (1971). Role of $\gamma$-aminobutyric acid in the extrapyramidal motor system. 2. Some evidence for the existence of a type of GABA-rich strio-nigral neurons. Exp. Brain Res. 14, 95-104.

MASON, S.T. and FIBIGER, H.C. (1979). On the specificity of kainic acid. Science, 204, 1339-1341.

NAGY, J.I. (1979). Unpublished Ph.D. thesis.

NAGY, J.I., CARTER, D.A. and FIBIGER, H.C. (1978a). Anterior striatal projections to the globus pallidus, entopeduncular nucleus and substantia nigra in the rat: The GABA connection. Brain Res. 158, 15-29.

NAGY, J.R., CARTER, D.A., LEHMANN, J. and FIBIGER, H.C. (1978b). Evidence for a GABA-containing projection from the entopeduncular nucleus to the lateral habenula in the rat. Brain Res. 145, 360-364.

NAGY, J.I. and FIBIGER, H.C. (1980). A striatal source of glutamic acid decarboxylase activity in the substantia nigra. Brain Res. 187, 237-242.

NAGY, J.I., VINCENT, S.R., LEHMANN, J., FIBIGER, H.C. and McGEER, E.G. (1978c). The use of kainic acid in the localization of enzymes in the substantia nigra. Brain Res. 149, 431-441.

VINCENT, S.R., HATTORI, T. and McGEER, E.G. (1978). The nigrotectal projection: a biochemical and ultrastructural characterization. Brain Res. 151, 159-164. 